\title{
Why Conduct a Spiritual Assessment? ATheoretical Foundation for Assessment
}

\author{
David R. Hodge
}

\begin{abstract}
In spite of increased interest in spirituality, the concept of a spiritual assessment remains a questionable practice in the eyes of many social workers. This paper develops five rationales to underscore the importance of including spirituality in assessment. These reasons can be summarized as follows: spiritual assessment provides insight into clients' worldviews, serves as a vehicle to identify strengths, and demonstrates respect for client autonomy. In addition, the professi on's ethics implicitly recommend the administration of a spiritual assessment and, for a growing number of accrediting organizations and agencies, it is expli citly recommended. This paper concludes by discussing theimplications for practitioners and educators.
\end{abstract}

Keywords: Assessment, spirituality, religion, spiritual assessment, religious histories

A ssessment is a central component of direct social work practice. While numerous definitions exist, assessment can be understood as the process of gathering, analyzing, and synthesizing information into a concise picture that provides the basis for action decisions (Hepworth, Rooney \& Larsen, 2002; Rauch, 1993). It is the assessment process that provides the foundation for the resulting therapeutic enterprise. The content areas explored during assessment provide the basis for, and give direction to, subsequent practice decisions.

Recently, interest in the topic of spiritual assessment has emerged, perhaps particularly among practitioners and students (Canda \& Furman, 1999; Derezotes, 1995; Sheridan \& Amato-von Hemert, 1999). Traditionally, however, the assessment of spirituality has been ignored (DeCoster \& Burcham, 2002). Many social work practitioners believe that "the notion of spirituality is irrelevant to everyday life" or is even harmful (Gotterer, 2001, p. 191). Time constraints limit the material that can be covered during assessment, and professional consensus has traditionally suggested that domains other than spirituality be explored during the assessment process.

Echoing this line of thought, Clark (1994) has argued that social work education should not address spirituality. While many disagree with this perspective (Canda \& Furman, 1999), Clark's views seem to reflect the professional

David Hodge, Ph.D., is a Post-Doctoral Fellow with the Program for Research on Religion and Urban Civil Society, University of Pennsylvania, Philadelphia, PA 19104.

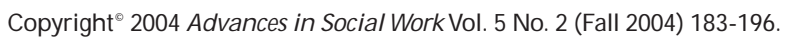

Indiana University School of Social Work. 
reality that currently exists (DeCoster \& Burcham, 2002). Studies have repeatedly demonstrated that most social workers have received little or no training in spirituality or religion during their graduate education (Canda \& Furman, 1999; Furman, Benson, Grimwood \& Franz, in press; Murdock, 2004; Sheridan \& Amato-von Hemert, 1999). Given the central role that education plays in socializing future practitioners into what is considered accepted social work practice, the profession sends the message that spirituality is, at best, a marginal content area to be considered during the assessment process.

The question detractors implicitly ask-why should time be devoted to assessing spirituality?-is one that deserves an answer. The purpose of this paper is to answer this question. More specifically, this paper delineates the reasons why a spiritual assessment should be conducted, and concurrently, implicitly emphasizes the need for training so that social workers are equipped to perform such assessments in a spiritually competent manner. I begin by defining spirituality and religion, noting how these two constructs relate to spiritual assessment.

\section{DEFINITIONS}

Although various definitions of spirituality and religion exist, they are generally seen as distinct but overlapping constructs (Canda \& Furman, 1999; Carroll, 1998). Ai (2002), for example, views them as interconnected but distinguishable concepts, a view shared by Miller, the chair of the National Institutes of Health (NIH) Working Group on Research on Spirituality, Religion and Health (Miller \& Thoresen, 2003). Consistent with this understanding, spirituality can be viewed as ontologically driven, striving for union or relation with God, or ultimate transcendent reality, while religion can be understood to be the external expression of faith that unites an individual with a moral community (Joseph, 1988; Stanard, Sandhu \& Painter, 2000).

Debate exists over whether spirituality or religion is the broader construct (Pargament, 1999), and much empirical work tends to treat the two constructs as synonymous (Miller \& Thoresen, 2003). When referencing the others' work, I have generally followed the usage developed by the underlying author(s). In general, however, I view spirituality as the broader construct, particularly when referring to spiritual assessment. Based upon this understanding, a spiritual assessment incorporates religion. Personally oriented spiritual dimensions are explored, along with any community oriented religious dimensions that may exist as an expression of one's spirituality.

The reasons why social workers should be equipped to conduct a spiritual assessment are discussed next. These reasons, which are inter-related, can be summarized as follows: knowledge of clients' worldviews, interest in the strengths perspective, respect for client autonomy, professional ethics, and accrediting and agency requirements.

\section{KNOWLEGE OF CLIENTS' WORLDMEWS}

One of the purposes of assessment is to gather information about the client's worldview. Understanding how the client views reality assists practitioners in 
building therapeutic rapport, suggesting interventions that are more likely to be adopted, and avoiding interactions that place the therapeutic relationship at risk. Interactions that are incongruent with clients' worldviews can result in clients terminating therapy or, in some instances, even cause harm to clients.

For many people, spirituality provides an interpretive framework for understanding reality that informs them of who they are and how they should live (Maslow, 1968). Put differently, for many individuals, spirituality is central to their personal ontology (Haynes, 2001). As observers have noted, clients' spiritual worldviews can affect attitudes and practices in a number of areas, including animals, child care, diet, marital relations, medical care, military participation, recreation, schooling, and many other areas of significance to social workers (Pellebon \& Anderson, 1999; Rey, 1997).

It is important to note that spirituality is the salient organizing principle for a significant number of individuals. Approximately $95 \%$ of the general public profess belief in God or the Transcendent and $82 \%$ report that they feel the need to grow spiritually (Gallup \& Lindsay, 1999). Approximately $60 \%$ of the public report that religion is very important to them, and approximately a third consider religion to bethe most important influence in their lives (Walsh, 1999). Furthermore, interest in spirituality appears to be increasing (Miller \& Thoresen, 2003).

In addition, the United States is becoming increasingly diverse in terms of its religious tapestry (Melton, 1999). For instance, the number of Muslims (Smith, 1999) and Hindus (Williams, 1997) has increased dramatically since immigration policies were changed in the mid-1960s. While secularists and adherents of mainline Protestant denominations may still dominate the centers of social power in the United States (Hunter, 1991; McCullough, Weaver, Larson \& Aay, 2000), the underlying society is populated by an increasingly diverse array of religious worldviews.

As Pellebon and Anderson (1999) note, it is essential to understand the meaning of life from the perspective of spiritually based clients. Conducting a spiritual assessment provides a window into the client's worldview. To provide effective, client-centered services for persons for whom spirituality plays an important role in shaping their perceptions, spiritual assessment is a prerequisite (Richards \& Bergin, 1997). This is particularly the case for those who adhere to non-dominant worldviews (Koenig, 1998; Richards \& Bergin, 2000; Van Hook, Hugen \& Aguilar, 2001). If spiritual assessment is disregarded, therapy may, at best, fail to be as effective as it might otherwise be and, at worst, result in harm to the client. As has been noted among Hindus, for example, the application of typical Western secular values and related interventions may cause "confusion and further negative affect" (Reddy \& Hanna, 1998, p. 393).

Put more positively, conducting a spiritual assessment affords practitioners the opportunity to gather the necessary information that can be used to build rapport and design strategies that clients may be more inclined to implement (Gotterer, 2001). By suggesting interventions that are congruent with, and even resonate with clients' spiritual worldview, clients' sense of ownership is enhanced, resulting in greater likelihood of client implementation and follow- 
through (Hepworth, et al., 2002). This dynamic may be even more likely to occur if interventions are based upon clients' spiritual strengths.

\section{INTEREST IN THE STRENGTHSPERSPECTIVE}

Interest in the strengths perspective has continued to grow (Saleebey, 1997; 2000). This perspective emphasizes focusing on clients' assets rather than deficits during the assessment process. A measure of the strengths perspective's influence is that even traditional texts on social work practice emphasize that a key element of assessment is identifying clients' strengths (Hepworth, et al., 2002). Once strengths are identified in the assessment process, they can be operationalized to ameliorate problems.

While historically devout spirituality has often been equated with psychopathology (Ellis, 1980; Freud, 1964 [1927]), this opinion is no longer scientifically tenable. In the past few decades, a significant body of empirical research has developed, indicating that spirituality and religion are important assets (Koenig, McCullough \& Larson, 2001; Johnson, 2002; Pargament, 1997; Plante \& Sherman, 2001). In what is perhaps the best review to date, Koenig, McCullough and Larson (2001) examined more than 1,600 studies on the relationship between religion and physical and mental health outcomes. Religion was associated with a wide array of salutary outcomes.

General Social Survey (GSS) data suggests that religious strengths are relatively common among the general population (Davis, Smith \& Marsden, 1998). Some $42 \%$ of the general public report finding strength and comfort in religion at least every day, with an additional $17 \%$ indicating that they find strength most days. Only 14\% report that they never or almost never find strength in their religion. Similarly, some $54 \%$ of the population feel that their religious community is very helpful.

In addition, spiritual assets may be particularly salient among disadvantaged populations, which may help explain why historically spirituality has often been associated with psychopathology. Relative to the general public, research indicates that spirituality plays a heightened role among African Americans, Hispanics, women, people who are elderly, and people who are poor (Davis \& Robinson, 1997; Gallup \& Lindsay, 1999; Pargament, 1997).

For instance, when respondents in 23 nations were asked to rank the importance of God in their lives on a 10-point scale, American blacks recorded the highest score of any group-9.04 (Gallup \& Castelli, 1989). Across an array of measures, black Americans exhibit higher levels of religious participation than white Americans (Taylor, Chatters, Jayakody \& Levin, 1996). According to one study, approximately $70 \%$ of African Americans attend church or a place of worship at least two or three times a month (Chatters \& Taylor, 1994).

As might be expected, various measures of spirituality and religion have been associated with a wide variety of salutary characteristics among African Americans, including academic achievement (Walker \& Dixon, 2002), civic engagement (Smidt, 1999), empowerment (Calhoun-Brown, 1998), female leadership (Robinson, 1996), manhood development (Watts, 1993), recovery from 
addiction (Turner, O’Dell \& Weaver, 1999), coping among the elderly (Johnson, 1995), and women (Mattis, 2002), as well as resiliency among children (Haight, 1998), single mothers (Brodsky, 1999), the poor (Nelson, 1997), the elderly (Wallace \& Bergeman, 2002), and victims of racism (Bowen-Reid \& Harrell, 2002). Similarly, spirituality/ religion have been associated with increased levels of interpersonal friendliness (Ellison, 1992), life satisfaction (Levin, Chatters \& Taylor, 1995), physical and emotional health (Stolley \& Koenig, 1997), positive self-perceptions (Ellison, 1993), quality of family life (Ellison, 1997), self-esteem (Maton, Teti, Corns \& Vieira-Baker, 1996), and the ability to handle the stress associated with having a child with disabilities (Rogers-Dulan, 1998) and having an infant hospitalized with a serious illness (Wilson \& Miles, 2001).

The importance of spiritual assets may become more pronounced during times of stress or difficulty, which may help explain why spirituality tends to play a more significant role among disenfranchised populations. Research suggests that spiritual coping resources may become more salient in the face of difficult situations (Pargament, 1997). This is important since social workers often encounter people when they are wrestling with problems.

Without a vehicle for identifying spiritual resources, however, spiritual strengths are likely to remain untapped, regardless of their importance in clients' lives (Ronnau \& Poertner, 1993). Clients who are animated by their spirituality are often concerned about being misunderstood by social workers, who are often presumed to be secular and, consequently, may bedisinclined to broach the topic themselves (Furman, Perry \& Goldale, 1996; Lyles, 1992). Clients who are adherents of subordinate faiths may be particularly hesitant to discuss spiritual strengths, unless practitioners create a context that suggests some degree of spiritual competency on the part of the practitioner (Kelly, Aridi \& Bakhtiar, 1996; Richards \& Bergin, 2000).

Spiritual assessment helps create such a context by implicitly sending the message that spirituality is an important and valued resource that can be used to address problems. As Cascio (1998) notes, it legitimizes the topic of spirituality in practice settings. Furthermore, the skill sets employed in the assessment process (e.g., empathy, curiosity, and authenticity) can help set clients who may be worried about sharing an intensely personal topic at ease (Pellebon \& Anderson, 1999). In short, spiritual assessment provides a mechanism for identifying important spiritual resources that may otherwise lie dormant. As will be discussed subsequently, it can also demonstrate respect for client self-determination.

\section{RESPECT FOR CLIENT AUTONOMY}

Respecting client autonomy is a central tenant of social work practice (Regehr \& Antle, 1997). Not only is a client's right to self-determination a "hallmark of the profession" (Cascio, 1998), but effective therapy is understood to be predicated upon a non-coercive therapeutic atmosphere in which the desires of the client are valued (Cornett, 1992; Richards \& Bergin, 1997).

Many clients desire to have their spiritual beliefs and values integrated into counseling settings (Arnold, Avants, Margolin \& Marcotte, 2002; Larimore, Parker \& Crowther, 2002; Privette, Quackenbos \& Bundrick, 1994). According to Gallup 
data reported by Bart (1998), $66 \%$ of the public would prefer to see a professional counselor with spiritual values and beliefs, while $81 \%$ wanted to have their own values and beliefs integrated into the counseling process. Among a sample of parents $(\mathrm{N}=70)$ whose children were receiving mental health services, $74 \%$ felt that spirituality was relevant to their child's problems and more than half (53\%) felt that therapists should consider spirituality in treatment (Mathai \& North, 2003).

Although more outcomestudies are needed, some clinical trails have examined the efficacy of incorporating clients' spiritual beliefs into the counseling project. Consistent with the research cited in the previous section, these studies indicate that spirituality is an important asset that can be marshaled to help ameliorate problems. With Muslims, for example, cognitive/ behavioral therapy modified with beliefs drawn from the Koran has been effectively used to address anxiety disorders (Azhar, Varma \& Dharap, 1994), bereavement (Azhar \& Varma, 1995a), and depression (Azhar \& Varma, 1995b). This modality has also been effective in altering the characteristics and content of schizophrenic symptoms (e.g., auditory hallucinations) that have persisted despite the administration of anti-psychotic medications (Wahass \& Kent, 1997). Similarly, positive outcomes have been found when treating depression among Christians (Hawkins, Tan \& Turk, 1999; Propst, 1996), perfectionism among Mormons (Richards, Owen \& Stein, 1993), neurosis among Chinese Taoists (Xiao, Young \& Zhang, 1998), and stress among a religiously heterogeneous sample (Nohr, 2000).

Social workers have an obligation to respond to clients' desires to integrate their spirituality into therapy (Northcut, 2000). For those clients who want to integrate their spiritual beliefs and values into therapy, spiritual assessment provides a way to honor their right to self-determination. Spiritual assessment provides a forum for identifying relevant spiritual beliefs and practices that can be incorporated into various co-selected action strategies. Conducting a spiritual assessment demonstrates responsiveness to clients' aspirations to integrate spirituality, allowing social workers to fulfill a primary ethical value. While clients' right to self-determination is a central social work value, the profession's ethical code also lists a number of other standards that are pertinent to spiritual assessment.

\section{ETHICS}

Although professional codes of ethics are designed for many purposes, a primary function is to guide practitioners' conduct (Freeman, 2000). As the NASW Code of Ethics (1999) states, the Code socializes new practitioners to the profession's core values, which are manifested in a set of standards that should guide social work practice. Every task, including assessment, should be informed by the profession's ethical standards (Morales \& Sheafor, 2004).

The NASW Code of Ethics (1999) lists four standards that explicitly mention religion (1.05c, 2.01b, 4.02, and 6.04d) and at least two standards that implicitly refer to religion (1.05a, 1.05b). Social workers are ethically bound to obtain education about religious diversity and the oppression religious people encounter in various forums (1.05c), avoid unwarranted negative criticism and derogatory language based upon religion (2.01b; c.f. 1.12), refrain from facilitating any form of religious discrimination (4.02), and actively work to prevent and eliminate reli- 
gious discrimination (6.04d). Social workers should also recognize the strengths that exist in religious cultures (1.05a) and demonstrate competence and sensitivity in their service provision to such groups (1.05b).

The implementation of these standards in practice settings implicitly calls for a spiritual assessment. As noted above, it is difficult to recognize spiritual strengths without conducting a spiritual assessment to identify them (Ronnau \& Poertner, 1993). Similarly, to avoid inadvertently discriminating or oppressing people of faith, it is frequently necessary to have some understanding of the client's spiritual worldview (Reddy \& Hanna, 1998; Richards \& Bergin, 2000).

Standards 1.05 and 6.04, in particular, have played a central role in the development of the NASW Standards for Cultural Competence in Social Work Practice (2001). Cultural Competence standard 4 instructs social workers to conduct a comprehensive assessment, noting clients' cultural norms and strengths, and utilizing the resulting information gained during assessment to develop culturally relevant intervention plans. In keeping with the Code of Ethics, religious cultures are specifically mentioned in the cultural competence standards.

In short, the NASW Code of Ethics (1999) standards that address religion implicitly highlights the need for spiritual assessment. Indeed, it is difficult to see how social workers can comply with the Code of Ethics in practice settings without conducting a spiritual assessment. Spiritual assessment can provide the necessary information that facilitates compliance with the ethical standards. While supplementary information, (e.g., an understanding of clients' spiritual cultures [Richards \& Bergin, 2000]) and skill sets (e.g., knowledge of religious countertransference [Genia, 2000]) may be required to fully comply with the standards that address religion, conducting a spiritual assessment plays a foundational role in assisting practitioners conform to the profession's ethical values. While the values propagated in the Code of Ethics are intended to guide practitioners' conduct, the code also acknowledges that other factors, such as accrediting regulations and agency polices, should also guide social work practice.

\section{ACCREDITING AND AGENCY REQUIREMENTS}

As implied above, interest in spirituality has increased in many sections of society, including professional disciplines (Gallup \& Lindsay, 1999). For instance, Koenig, McCullough and Larson (2001) report that more than half the medical schools in the United States are training physicians to address spirituality in the course of their medical practices. Animated by many of the reasons discussed above, recognition seems to be growing among the hel ping professions regarding the importance of spirituality in client care (Koenig, et al., 2001; Miller \& Thoresen, 2003).

Accrediting organizations and agencies are reflecting this recognition by recommending that all clients receive a spiritual assessment. Perhaps the most notable example is the Joint Commission on Accreditation of Healthcare Organizations (JCAHO), which is one of the major healthcare accrediting agencies in the United States. JCAHO accredits most hospitals and many other mental health providers in the United States. 
JCAHO (2002) recommends that social workers conduct a spiritual assessment. At a minimum, assessment should determine the client's denomination and any spiritual beliefs and practices that are important to the client. The purpose of the initial assessment is twofold: to identify the effect of clients' spirituality on service provision, if any, and to determine if a further, more extensive spiritual assessment is required.

Thus, in an increasing number of instances, social workers are required to conduct a spiritual assessment. This rationale for conducting a spiritual assessment differs in character from the previously discussed reasons. The four reasons discussed above are based upon either an appeal to sound social work practice or professional ethics or some combination of the two. The final reason differs in the sense that appeal is absent. Conducting a spiritual assessment is important, because, in many cases, it may be part of the job description.

\section{DISCUSSION AND IMPLICATIONS}

The theoretical rationales discussed above have direct implications for both practitioners and educators. Ideally, social work practitioners should generally be conducting a spiritual assessment. In keeping with the JCAHO (2002) recommendations, initial assessment might consist of a brief exploration of spiritual beliefs, practices, and degree of involvement in a religious community, focusing on how these factors relate to the precipitating event that resulted in the social worker's presence. This brief assessment can be integrated into existing assessment protocols. In cases where the client's spirituality seems particularly relevant to the present context, a more complete assessment can be administered.

Although the frequency with which practitioners administer spiritual assessments is unclear, broad support for conducting a spiritual assessment seems to exist among practitioners and students. Among a national sample of NASW affiliated practitioners $(\mathrm{N}=2,069)$, almost $60 \%$ agreed that an exploration of spirituality and religion should be part of the intake/ assessment process (Canda \& Furman, 1999). Among a sample of graduate students drawn from two universities ( $N=208)$, approximately $93 \%$ of respondent students considered it appropriate to gather information on clients' spiritual backgrounds and roughly $68 \%$ reported conducting such as assessment themselves (Sheridan \& Amato-von Hemert, 1999).

While social workers may be open to addressing spirituality in practice settings (Canda \& Furman, 1999; Derezotes, 1995; Murdock, 2004; Sheridan, Bullis, Adcock, Berlin \& Miller, 1992), it remains an open question how well trained they are to engage in such activities. Given that studies have repeatedly demonstrated that most social workers have received little or no training on spirituality or religion during their graduate education (Canda \& Furman, 1999; Furman, et al., in press; Sheridan \& Amato-von Hemert, 1999), it is unsurprising that research suggests that practitioners are unequipped to conduct a spiritual assessment.

In the study of NASW affiliated practitioners cited above, only $17 \%$ agreed that social workers in general have the knowledge to address spiritual issues (Canda \& Furman, 1999). Summarizing their findings, the authors of the study concluded that, while many practitioners recognize the importance of spirituality, they do 
not feel adequately prepared to address the topic in practice settings. In their examination of graduate students' attitudes about client religion ( $N=124)$, DeCoster and Burcham (2002) came to a similar conclusion. These researchers suggested that educators had not effectively integrated religious content into the curriculum, resulting in respondents who were uncomfortable assessing clients' religion.

As Cascio (1998) observes, in-service workshops, programs, and continuing educational forums are needed to acquaint practitioners with the information needed to conduct spiritual assessments in an ethically competent manner that respects client autonomy. Perceptions that spirituality can be pathological still exist, with the spiritual worldviews affirmed by African Americans, people who are elderly, and other disadvantaged populations likely being most at risk for being classified as pathological. Sheridan and Amato-von Hemert (1999) found that roughly $62 \%$ of respondent students believed that it was appropriate to share their own spiritual beliefs with clients. While more research is needed to explore this finding, it is possible that students who feel that others' spiritual beliefs are unhealthy may feel the need to challenge those beliefs in an attempt to convert clients to what they consider to be more beneficial beliefs. Training is needed to ensure that social workers respect clients' spiritual beliefs and refrain from attempting to change those beliefs that they consider pathological, dysfunctional, or simply wrong. By training practitioners to work within clients' worldviews, partnering with clergy members from the clients' faith, if necessary, the profession's commitment to autonomy can be respected.

Similarly, training is needed for faculty members who may also be uncomfortable discussing spirituality. As has been widely noted (Canda \& Furman, 1999), content on spirituality and religion needs to be integrated into graduate education curricula. While one of the purposes of spiritual assessment is to illuminate clients' values, providing education about religious diversity as the NASW Code of Ethics (1999) prescribes, assists future social workers in understanding the process by providing them with a working knowledge of commonly held beliefs and practices (Richards \& Bergin, 2000).

It is important to acknowledge that social work education is making progress in this area. The number of programs offering courses on spirituality is increasing. At least 50 programs now include content on spirituality, up from a handful in 1990 (Miller, 2001).

These efforts need to be expanded and built upon. While elective courses on spirituality serve an important purpose, ideally, all practitioners should be equipped to conduct a spiritual assessment in a spiritually competent manner as part of their graduate training. Given that assessment is a topic already discussed in practice courses, content could be expanded to include spirituality with minimal restructuring. Spirituality can be presented as one dimension of human existence, with students being taught to respect spiritual cultures in the same manner that they are taught to respect other cultures (Cascio, 1998).

As is the case with other expressions of diversity, an exploration of spirituality will not be relevant to some clients. For many clients, however, spirituality is an important life dimension, while for others, it is a central dimension that informs 
all other areas of existence. For clients who fall into the latter categories, a spiritual assessment is critical for the provision of client-centered services that reflect the profession's ethical standards. Also critical is the need for social work education to equip future practitioners with conducting such assessments in a spiritually competent manner.

\section{References}

Ai, A.L. (2002). Integrating spirituality into professional education: A challenging but feasible task. Journal of Teaching in Social Work, 22(1/2), 103-130.

Arnold, R.M., Avants, S.K., Margolin, A.M., \& Marcotte, D. (2002). Patient attitudes concerning the inclusion of spirituality into addiction treatment. Journal of Substance Abuse Treatment, 23, 319-326.

Azhar, M.Z., \& Varma, S.L. (1995a). Religious psychotherapy as management of bereavement. Acta Psychiatrica Scandinavica, 91, 233-235.

Azhar, M.Z., \& Varma, S.L. (1995b). Religious psychotherapy in depressive patients. Psychotherapy and Psychosomatics, 63, 165-168.

Azhar, M.Z., Varma, S.L., \& Dharap, A.S. (1994). Religious psychotherapy in anxiety disorder patients. Acta Psychiatrica Scandinavica, 90, 1-2.

Bowen-Reid, T.L., \& Harrell, J.P. (2002). Racist experiences and health outcomes: An examination of spirituality as a buffer. Journal of Black Psychology, 28(1), 18-36.

Brodsky, A.E. (1999). "Making it": The components and process of resilience among urban, AfricanAmerican, single mothers. American Journal of Orthopsychiatry, 69(2), 148-160.

Calhoun-Brown, A. (1998). While marching to Zion: Otherworldliness and racial empowerment in the black community. Journal for the Scientific Study of Religion, 37(3), 427-439.

Canda, E.R., \& Furman, L.D. (1999). Spiritual diversity in social work practice. New York: The Free Press.

Carroll, M.M. (1998). Social work's conceptualization of spirituality. Social Thought, 18(2), 1-13.

Cascio, T. (1998). Incorporating spirituality into social work practice: A review of what to do. Families in Society, 79(5), 523-532.

Chatters, L.M., \& Taylor, R.J. (1994). Religious involvement among older African-Americans. In J.S. Levin (Ed.), Religion in aging and health: Theoretical foundationsand methodological frontiers (pp. 196-230). Thousand Oaks, CA: Sage Publications.

Clark, J. (1994). Should social work education address religious issues? No! Journal of Social Work Education, 30(1), 11-16.

Cornett, C. (1992). Toward a more comprehensive personology: Integrating a spiritual perspective into social work practice. Social Work, 37(2), 101-102.

Davis, J.A., Smith, T.W., \& Marsden, P.V. (1998). General social surveys, 1972-1998: Cumulative codebook. Storrs, CT: The Roper Center for Public Opinion Research.

Davis, N.J., \& Robinson, R.V. (1997). A war for America's soul? The American religious landscape. In R.H. Williams (Ed.), Cultural wars in American politics (pp. 39-61). New York: Aldine De Gruyter.

DeCoster, V.A., \& Burcham, S. (2002). Graduate social work students' attitudes about client religion. Social Thought, 21(2), 75-97.

Derezotes, D.S. (1995). Spirituality and religiosity: Neglected factors in social work practice. Arête, 20(1), 1-15.

Ellis, A. (1980). Psychotherapy and atheistic values: A response to A.E. Bergin's "psychotherapy and religious values." Journal of Consulting and Clinical Psychology, 48(5), 635-639.

Ellison, C.G. (1992). Are religious people nice? Evidence from the national survey of Black Americans. Social Forces, 71(2), 411-430. 
Ellison, C.G. (1993). Religious involvement and self-perception among Black Americans. Social Forces, 71(4), 1027-1055.

Ellison, C.G. (1997). Religious involvement and the subjective quality of family life among African Americans. In R.J. Taylor, J.S. Jackson, \& L.M. Chatters (Eds.), Familylifein black America (pp. 117-129). Thousand Oaks, CA: Sage.

Freeman, S.J. (2000). Ethics: An introduction to philosophy and practice. Belmont, CA: Wadsworth.

Freud, S. (1964 [1927]). The future of an illusion, civilization and its discontents and other works (J. Strachey, Trans.) (Vol. 21). London: Hogarth Press.

Furman, L.D., Perry, D., \& Goldale, T. (1996). Interaction of Evangelical Christians and social workers in the rural environment. Human Services in the Rural Environment, 19(3), 5-8.

Furman, L.D., Benson, P.W., Grimwood, C., \& Franz, J. (In press). Religion and spirituality at the millennium: Descriptive findings from a survey of UK social workers. British Journal of Social Work.

Gallup, G.J., \& Castelli, J. (1989). The people's religion: American faith in the 90s. New York: Macmillan.

Gallup, G.J., \& Lindsay, D.M. (1999). Surveying the religious landscape. Harrisburg, PA: Morehouse Publishing.

Genia, V. (2000). Religious issues in secularly based psychotherapy. Counselingand Values, 44(3), 213-221.

Gotterer, R. (2001). The spiritual dimension in clinical social work practice: A client perspective. Families in Society, 82(2), 187-193.

Haight, W.L. (1998). "Gathering the spirit” at first Baptist church: Spirituality as a protective factor in the lives of African American children. Social Work, 43(3), 213-221.

Hawkins, R.S., Tan, S.-Y., \&Turk, A.A. (1999). Secular versus Christian inpatient cognitive-behavioral therapy programs: Impact on depression and spiritual well-being. Journal of Psychology and Theology, 274(4), 309-318.

Haynes, D.T. (2001). Mormonism. In M. Van Hook, B. Hugen, \& M. Aguilar (Eds.), Spi rituality within religious traditions in social work practice (pp. 251-272). Pacific Grove, CA: Brooks/Cole.

Hepworth, D.H., Rooney, R.H., \& Larsen, J.A. (2002). Direct social work practice (6 $6^{\text {th }}$ ed.). Pacific Grove, CA: Brooks/Cole.

Hunter, J.D. (1991). CultureWars. New York: BasicBooks.

JCAHO. (2002). Spiritual Assessment. In Standards-Frequently asked questions. Retrieved 21/03/02, from: http://www.jcaho.org/standard/pharmfaq_mpfrm.html.

Johnson, B.R. (2002). Objectivehope[Assessing the effectiveness of faith-based organizations: A review of the literature]. Philadelphia, PA: Center for Research on Religion and Urban Civil Society.

Johnson, C.L. (1995). Determinants of adaptation of oldest old black Americans. Journal of Aging Studies, 9(3), 231-244.

Joseph, M.V. (1988). Religion and social work practice. Social Casework: The Journal of Contemporary Social Work, 69(7), 443-452.

Kelly, E.W., Aridi, A., \& Bakhtiar, L. (1996). Muslims in the United States: An exploratory study of universal and mental health values. Counseling and Values, 40(3), 206-218.

Koenig, H.G., McCullough, M.E., \& Larson, D.B. (2001). Handbook of religion and health. New York: Oxford University Press.

Koenig, H.G. (Editor). (1998). Handbook of religion and mental health. New York: Academic Press.

Larimore, W.L., Parker, M., \& Crowther, M. (2002). Should clinicians incorporate positive spirituality into their practices? What does the evidence say? Annals of Behavioral Medicine, 24(1), 69-73.

Levin, J.S., Chatters, L.M., \& Taylor, R.J. (1995). Religious effects on health status and life satisfaction among black Americans. Psychological Sciences \& Social Sciences, 50(3), 154-163.

Lyles, M.R. (1992). Mental health perceptions of black pastors: Implications for psychotherapy with black patients. Journal of Psychology and Christianity, 11(4), 368-377.

Maslow, A.H. (1968). Toward a psychology of being. Princeton: D. Van Nostrand Company. 
Mathai, J., \& North, A. (2003). Spiritual history of parents of children attending a child and adolescent mental health service. Australian Psychiatry, 11(2), 172-174.

Maton, K.I., Teti, D.M., Corns, K.M., \& Vieira-Baker, C.C. (1996). Cultural specificity of support sources, correlates and contexts: Three studies of African American and Caucasian youth. American Journal of Community Psychology, 24(4), 551-587.

Mattis, J. (2002). Religion and spirituality meaning-making and coping experiences of African American women: A qualitative analysis. Psychology of Women Quarterly, 26, 309-321.

McCullough, M.E., Weaver, A.J., Larson, D.B., \& Aay, K.R. (2000). Psychotherapy with mainline Protestants: Lutheran, Presbyterian, Episcopal/Anglican, and Methodist. In P.S. Richards \& A.E. Bergin (Eds.), Handbook of psychotherapy and religious diversity (pp. 105-129). Washington, D.C.: American Psychological Association.

Melton, J.G. (1999). Theencyclopedia of American religions (6 $6^{\text {th }}$ ed.). London: Gale Research.

Miller, D.W. (2001, May 12). Programs in social work embrace the teaching of spirituality. The Chronicle of Higher Education, The Faculty, A12. Retrieved November 24, 2003, from: http://chronicle.com/prm/ weekly/v47/i36/36a01201.htm.

Miller, W.R., \& Thoresen, C.E. (2003). Spirituality, religion, and health: An emerging research field. American Psychologist, 58(1), 24-35.

Morales, A.T., \& Sheafor, B.W. (2004). Social work: A profession of many faces (10 ed.). Boston: Allyn \& Bacon.

Murdock, V. (2004, February 27- March 1). Religion and spirituality in gerontological social work practice: Results of a national survey. Paper presented at the [Fifth annual program meeting] Council on Social Work Education, Anaheim, CA.

NASW Code of Ethics. (1999). Retrieved 7/28/03, from: http://www.socialworkers.org/pubs/ code/ code.asp

NASW Standards for Cultural Competence in Social Work Practice. (2001). Retrieved Accessed 9/24/2003, from NASW Press: http://www.socialworkers.org/sections/credentials/cultural_comp.asp

Nelson, T.J. (1997). He made a way out of no way: Religious experience in an African-American congregation. Review of the Religious Research, 39(1), 5-26.

Nohr, R.W. (2000). Outcome effects of receiving a spiritually-informed vs. a standard cognitive behavioral stress-management workshop. Unpublished doctoral dissertation, Marquette University.

Northcut, T.B. (2000). Constructing a place for religion and spirituality in psychodynamic practice. Clinical Social Work Journal, 28(2), 155-169.

Pargament, K.I. (1997). The psychology of religion and coping. New York: Guilford Press.

Pargament, K.I. (1999). The psychology of religion and spirituality?Yes and no. The International Journal for the Psychology of Religion, 9(1), 3-16.

Pellebon, D.A., \& Anderson, S.C. (1999). Understanding the life issues of spiritually-based clients. Families in Society, 80(3), 229-238.

Plante, T.G., \& Sherman, A.C. (Editors). (2001). Faith and health. New York: Guilford Press.

Privette, G., Quackenbos, S., \& Bundrick, C.M. (1994). Preferences for religious and nonreligious counseling and psychotherapy. Psychological Reports, 75, 539-547.

Propst, L.R. (1996). Cognitive-behavioral therapy and the religious person. In E.P. Shafranske (Ed.), Religion and the clinical practice of psychology (pp. 391-407). Washington, D.C.: American Psychological Association.

Rauch, J.B. (1993). Assessment: A sourcebook for social work practice. Milwaukee: Families International.

Reddy, I., \& Hanna, F.J . (1998). The lifestyle of the Hindu woman: Conceptualizing female clients of Indian origin. The Journal of Individual Psychology, 54(3), 384-398.

Regehr, C., \& Antle, B. (1997). Coercive influences: Informed consent in court-mandated social work practice. Social Work, 42(3), 300-306.

Rey, L.D. (1997). Religion as invisible culture: Knowing about and knowing with. Journal of Family Social Work, 2(2), 159-177. 
Richards, P.S., \& Bergin, A.E. (1997). A spiritual strategy. Washington, D.C.: American Psychological Association.

Richards, P.S., \& Bergin, A.E. (Eds.). (2000). Handbook of psychotherapy and religious diversity. Washington, D.C.: American Psychological Association.

Richards, P.S., Owen, L., \& Stein, S. (1993). A religiously oriented group counseling intervention for selfdefeating perfectionism: A pilot study. Counseling and Values, 37, 96-104.

Robinson, F. (1996). African American women leaders in the community college: Where they get their strengths. Thresholdsin Education, 22(1), 49-52.

Rogers-Dulan, J. (1998). Religious connectedness among urban African American families who have a child with disabilities. Mental Retardation, 36(2), 91-103.

Ronnau, J., \& Poertner, J. (1993). Identification and use of strengths: A family system approach. Children Today, 22(2), 20-23.

Saleebey, D. (1997). The strengths approach to practice. In D. Saleebey (Ed.), The strengths perspectivein social work practice (pp. 49-57). White Plains, NY: Longman.

Saleebey, D. (2000). Power in the people: Strengths and hope. Advances in Social Work, 1(2), 127-136.

Sheridan, M.J., \& Amato-von Hemert, K. (1999). The role of religion and spirituality in social work education and practice: A survey of student views and experiences. Journal of Social Work Education, 35(1), 125-141.

Sheridan, M.J., Bullis, R.K., Adcock, C.R., Berlin, S.D., \& Miller, P.C. (1992). Practitioners' personal and professional attitudes and behaviors toward religion and spirituality: Issues for education and practice. Journal of Social Work Education, 28(2), 190-203.

Smidt, C. (1999). Religion and civic engagement: A comparative analysis. Annals of the American Academy of Political and Social Science, 565, 176-192.

Smith, J.I. (1999). Islam in America. New York: Columbia University Press.

Stanard, R.P., Sandhu, D.S., \& Painter, L.C. (2000). Assessment of spirituality in counseling. Journal of Counseling and Development, 78(2), 204-210.

Stolley, J.M., \& Koenig, H. (1997). Religion/spirituality and health among elderly African Americans and Hispanics. Journal of Psychosocial Nursing, 35(11), 32-38.

Taylor, R.J., Chatters, L.M., Jayakody, R., \& Levin, J.S. (1996). Black and white differences in religious participation: A multisample comparison. Journal for theScientific Study of Religion, 35(4), 403-410.

Turner, N.H., O'Dell, K.J., \&Weaver, G.D. (1999). Religion and the recovery of addicted women. Journal of Religion and Health, 38(2), 137-148.

Van Hook, M., Hugen, B., \& Aguilar, M.A. (Editors). (2001). Spirituality within religious traditions in social work practice. Pacific Grove, CA: Brooks/ Cole.

Wahass, S., \& Kent, G. (1997). The modification of psychological interventions for persistent auditory hallucinations to an Islamic culture. Behavioral and Cognitive Psychology, 25, 351-364.

Walker, K.L., \& Dixon, V. (2002). Spirituality and academic performance among African American college students. Journal of Black Psychology, 28(2), 107-121.

Wallace, K., \& Bergeman, C. (2002). Spirituality and religiosity in a sample of African American elders: A life story approach. Journal of Adult Development, 9(2), 141-154.

Walsh, F. (1999). Religion and spirituality. In F. Walsh (Ed.), Spiritual resources in family therapy (pp. 3-27). New York: Gilford Press.

Watts, R.J. (1993). Community action through manhood development: A look at concepts and concerns from the frontline. American Journal of Community Psychology, 21(3), 333-359.

Williams, R.B. (1997). South Asian religions in the United States. In J.R. Hinnells (Ed.), A new handbook of living religions (pp. 796-818). New York: Penguin Books.

Wilson, S.M., \& Miles, M.S. (2001). Spirituality in African American mothers coping with a seriously ill infant. Journal of the Society of Pediatric Nurses, 6(3), 116-125. 
Xiao, S., Young, D., \& Zhang, H. (1998). Taoistic cognitive psychotherapy for neurotic patients: A preliminary clinical trail. Psychiatry and Clinical Neurosciences, 52(Supplemental), S238-S241.

\section{Author's Note:}

Address correspondence to: David Hodge, Ph.D., Program for Research on Religion and Urban Civil Society, University of Pennsylvania, Leadership Hall, 3814 Walnut Street, Philadelphia, PA 19104, USA. Email: dhodge@sas.upenn.edu 